\title{
A ESCRITA EMPOLADA EM O NOME DO BISPO: REPRESENTAÇÃO DA ELITE OU CONTRADIÇÃO NO DISCURSO?
}

\author{
- RENATA MANONI DE MELLO CASTANHO
}

\section{RESUMO}

O presente artigo busca pensar criticamente a linguagem rebuscada do narrador de $O$ nome do bispo (1985), romance de Zulmira Ribeiro Tavares. O encontro de Heládio - protagonista e representante de uma elite brasileira decadente - com a pobreza é ridicularizado pelo narrador no plano do enredo. No entanto, observa-se certo excesso na linguagem, que destoa da matéria tratada e pode ser pensado, nos movimentos de aproximação e distanciamento do narrador com seu protagonista e com outros personagens, em certos momentos como mimetismo de uma classe e, em outros, como discurso ornamental e, portanto, contraditório.

Palavras-chave: Romance brasileiro, representação, ponto de vista

\section{ABSTRACT}

The following paper proposes critical thinking on the over-elaborate language of the narrator in the novelO nome do bispo (1985) by Zulmira Ribeiro Tavares. The encounter with poverty by main character Heládio, a representative of a decadent Brazilian elite, is ridiculed in the plot by the narrator. However, it can be observed that a certain excess in the language strays from the given subject matter, and this will be thought out in movements of approach and distance between the narrator with its protagonist and other characters, in certain moments as a mimicry of a class and, in others, as ornamental speech and, therefore, contradictory.

Keywords: Brazilian novel, representation, point of view 


\section{ORNAMENTO E PONTO DE VISTA}

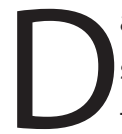

a espreguiçadeira do solário de um hospital particular, Heládio aguarda seu suco de laranja sem prever a súbita intrusão do mundo exterior, que transformará a até então aparentemente tranquila estadia na ocasião de uma intervenção cirúrgica. O mundo que constrói para si é completo e comedido, entre choferes, escrínios e reuniões familiares na antiga sala de retratos em uma mansão no Higienópolis, e os contrastes encontrados entre essa realidade e a outra, de fora, geram uma espécie de curto-circuito no brasileiro de nome respeitado, que passa a se sentir em situação de crescente desamparo.

O romance $O$ nome do bispo (1985) monta assim um esquema muito bem armado de uma antiga elite paulistana para então desmontá-lo na figura de Heládio Marcondes Pompeu e sua ridícula fissura anal. Se o contraste entre o registro alto e a feiura estetizada (e teorizada pela digressão kantiana no capítulo 7) já não choca tanto em pleno ano de 2017, talvez valha mais a pena pensar sobre o significado dessa escrita elevada - seja ela ornamental, mimética ou crítica.

De fato, chama a atenção que, querendo, literal e metaforicamente, jogar ao rés do chão a classe representada no seu protagonista, Zulmira Ribeiro Tavares incorpora a dicção desta na maior parte do livro, caindo em aparente contradição. Afinal, como alcançar um distanciamento crítico se a linguagem da obra, por si só, carrega a marca da distinção?

Observemos um dos trechos em que se percebe essa incorporação:

Liberto Heládio, por ato de vontade observa o teto. Olha-o com olhos que não são os do sono, uma vez que as pálpebras acham-se francamente descerradas, mas que também não são os olhos da vigília. A atenção com que Heládio examina o teto tem uma qualidade própria, de natureza particular, obtida por meio da mistura de algumas substâncias, entre as quais sem dúvida toma importante parte o conteúdo da cápsula ingerida, assim como sua própria química cerebral, sem todavia se poder afirmar que ambas a expliquem de forma satisfatória. Já a imaginação, ela mesma, poderia, com propriedade, ser chamada "substância"? (TAVARES, 2004, pp. 18-19)

A linguagem aqui vai se tornando rebuscada conforme o narrador se aproxima das complexas construções mentais de Heládio: as frases ficam mais longas, mais truncadas, mais trabalhadas, pois é dessa natureza a linha de pensamentos do personagem. Assim, no início do fragmento, temos a cena parada dele, que mira o teto: nada acontece, e o narrador se limita a descrever o que se vê no quarto de hospital. Em seguida, a câmera fecha nos olhos do paciente e, ainda 
mais perto, na atenção do seu olhar. Trata-se de uma aproximação investigativa, que busca os motivos desse olhar tão atento: os remédios, a própria natureza de Heládio? Na última frase, que é truncada e de significado complexo, já estamos imersos nos pensamentos do protagonista, com que a voz do narrador se confunde pelo discurso indireto livre.

O trecho continua:

Há também uma qualidade substancial, espessa, na irradiação azul que se dissemina pelo quarto e aos poucos pressiona o teto. Os ornamentos no friso de estuque, ovais, banhados pela luz, ganham a transparência de bagos. O teto solta-se, gira sobre si mesmo no eixo da luminária de vidro fosco e dá lugar a um outro: também antigo e alto, igualmente circundado por um friso com ornamentos, mas diverso sob vários aspectos.

(TAVARES, 2004, p. 19)

Aqui estamos totalmente no interior dos pensamentos de Heládio, e já não é o narrador quem guia a cena. A escrita correspondente ao ethos do protagonista torna-se tão ornamental quanto os objetos que descreve, em um esteticismo aparentemente gratuito. No entanto, é de se insistir que vemos o mundo pelos olhos do personagem, de forma que a esse parágrafo segue-se uma longa recordação de sua infância. O recurso à linguagem empolada, assim, vai ganhando força conforme adentramos as memórias do protagonista, o que, se não justifica, ao menos contextualiza o tom geral.

Para pensar os significados desse rebuscamento, tentaremos a princípio observar o narrador a partir do ponto de vista interno, das construções mentais de Heládio; em seguida, vamos compará-lo aos momentos em que a câmera circula entre outros personagens. Partindo desse contraste, procuraremos responder ao nosso problema crítico: a escrita elevada de $O$ nome do bispo contribui para construir uma representação de uma elite decadente ou, ao contrário, enfraquece seu teor crítico? Antes, porém, lembremos as linhas gerais do romance.

\section{RABO PRESO: O MEDO E A CULPA DE HELÁDIO}

Mais do que narrar a experiência cirúrgica de Heládio Pompeu, o romance O nome do bispo nos põe a par das transformações mentais do protagonista diante do ridículo da cirurgia e, principalmente, do (re)encontro com a"pobreza intimidante" no solário do hospital. É com isso que Heládio ilumina sua realidade de outra forma, atento que está, uma vez que seu "rabo-auscultador", ferido e em tratamento, o abre para uma nova forma de acordo com o mundo.

Antes dessa experiência, Heládio conseguia, bem ou mal, sustentar seu 
nome e pedigree sem maiores constrangimentos - apesar de considerado um "sensitivo" pela família Pompeu, mantém vivos o passado e a tradição que representa, como bem ilustra a maleta de mão que leva ao hospital. Lanterna, radinho de pilha, lápis, caneta, papel, caderneta de endereços, tesourinha de unhas, espelho de bolso, pente, livros, jornais e revistas (TAVARES, 2004, p. 11) servem menos para seus fins primeiros do que para moldar o caráter desse homem bem-nascido, consciente da importância da toalete, das precauções para passar algumas noites fora de casa, da conveniência de se manter informado e, por fim, do valor da leitura e da cultura. Com tudo ao alcance das mãos, Heládio é um homem à moda antiga, que busca aconchego e controle da situação, sem descomedimentos. O mesmo desejo por controle se expressa na apreciação da própria imagem no espelho do banheiro: leve bronzeado, corte de cabelo em dia, expressão de "acento terno", estatura, peso e, enfim, tudo, simplesmente tudo contribui para a manutenção da autoimagem de distinção dele.

No entanto, a necessidade da cirurgia surge como o primeiro fator que o desestabiliza: ser tratado como um doente, conviver com enfermeiros, pensar sobre seu bolo fecal e precisar depilar "lá embaixo" não só diminuem o ilustre Pompeu à condição de homem comum como também o tornam alguém que precisa de cuidados especiais e é inclusive alvo de questionamentos de outra ordem: "Você sabe que mesmo no tempo do São Bento eu nunca entrei na coisa, não é mesmo?" (TAVARES, 2004, p. 130), antecipa-se Heládio ao pensar que o melhor amigo pode questionar suas experiências sexuais.

Contudo, o que realmente põe às vistas as fraquezas do protagonista é o encontro com o homem de aparência "esforçada", pobre mesmo, que o ameaça em visita ao hospital ao confundi-lo com o dono de uma rede de supermercados, autor de injustiças sociais. Como veremos, só mesmo esse encontro indesejado poderia desencadear a ruína da imagem tão cuidadosamente construída por Heládio e seus antecessores, justamente porque revela o motivo desses privilégios - a exploração da classe trabalhadora.

É possível, assim, ler o romance $O$ nome do bispo considerando que ele nos conta duas histórias. A que está na superfície, à vista de todos, é a recuperação de Heládio após o diagnóstico da fissura anal, pois o livro começa com a entrada do personagem no hospital e termina com a sua saída. Trata-se de um recorte bem delimitado e que, por sua simplicidade ou falta de acontecimentos fortes, permite as rememorações, os pensamentos, as crises interiores do personagem. No entanto, essa narrativa acoberta a verdadeira história, central para o romance, que é a do encontro com a pobreza, tanto no solário quanto na revisitação de experiências anteriores e nas conversas com visitas ao hospital. Comecemos pelo primeiro.

Em uma cena montada como um thriller, Heládio sente "um cheiro... de pobreza" (TAVARES, 2004, p. 81) quando um homem desconhecido entra no pacato 
solário e deseja a sua morte, confundindo-o com outro paciente. A interrupção, repentina, ganha facilmente as proporções de um trauma: a narração rápida e confusa, a ativação de lembranças antigas e igualmente traumáticas, a decisão impulsiva de descer ao enterro do "paciente do escroto" e, enfim, o bloqueio provisório da experiência - que ele se nega a narrar para quase todos, com a exceção do confidente Mauro - nos mostram que esse rápido acontecimento é decisivo para a vida de Heládio ou, dito de outra forma, para o enredo do livro.

A ameaça vinda do homem no solário não é mero engano ou falha de comunicação. Ela o faz reviver uma situação constante na vida de qualquer herdeiro e representante da elite cultural e econômica do país, mas que nem todos percebem da mesma forma. Heládio se intimida por essa pobreza justamente porque tem consciência da distinção de classes e da exploração econômica e social, e só isso explica a associação do encontro no solário com outros eventos do passado. Sente medo da vingança, medo de perder seus bens, medo de ser desmascarado - sentimento que vem acompanhado de culpa, pois, se não era ele o real alvo do homem, a carapuça serviu muito bem. Essa culpa o distingue de outros grupos integrantes da elite: o coloca como sensitivo, como alguém que, por meio do interesse pela cultura, sabe que está em situação privilegiada e não se ilude com bobagens como a noção de meritocracia; no entanto, ao contrário do politicamente engajado Mauro, nada faz para mudar essa situação e mantém esse interesse apenas como um hobby.

A corda bamba de Heládio e sua fragilidade a partir do encontro no solário fazem ver que essa parcela da elite já não tem lugar social no país, pois ele é inteiramente ocupado pelo discurso liberal mais ou menos escancarado. Heládio pertence ao passado, lá tem seu "rabo preso" $\neg$ — um dos vários sentidos possíveis da riqueza vocabular de "rabo", metáfora bastante explorada no livro —, e para ele não há futuro, como bem mostra o desfecho da história.

\section{DENTRO, FORA: NARRADOR E PROTAGONISTA LADO A LADO}

Outro significado que a palavra "rabo" ganha no romance de Zulmira remete à conexão entre interior e exterior, noção que faz parte de diversos movimentos do narrador a partir do ponto de vista de Heládio. Interessa agora observar a complexidade dessa construção, para nos perguntarmos se ela é mais do narrador ou do personagem - dizendo em outras palavras, se estamos mais próximos de ornamento ou de mimetismo.

Para tanto, vamos olhar três momentos do livro em que ressoa essa noção intrincada que Heládio monta em sua cabeça como forma de organizar o mundo. O narrador, conforme perceberemos, está tão próximo do personagem que suas vozes se confundem. A pergunta que cabe fazer aqui é se essa aproximação é produtiva, se a complexidade das construções nos leva a algum lugar, se, afinal, 
a linguagem se sustenta criticamente.

A primeira cena que vamos observar é a da chegada de Heládio ao Hospital Santa Teresa. O narrador explica a mudança na vida do personagem a partir da doença que se desenvolveu "à margem da sua consciência", de uma dor física que teria atingido seu mundo interior ou "o mundo debruçado sobre o homem" (TAVARES, 2004, p. 8), em um movimento de fora para dentro. O rebuscamento está na ordem das ideias, e não necessariamente no vocabulário: o mundo debruça-se sobre o homem criando nele uma vida interior, que, no entanto, só se desperta em Heládio uma vez que a dor física (exterior) passa a influir em sua consciência (interior). Em seguida, de dentro do táxi, o personagem observa:

"Sim" - constata Heládio - "Nem uma pedra sobrou do veIho casario." Ou melhor, as que ficaram se ajustaram tão bem ao conjunto dos prédios novos que a ele hoje pertencem sem memória. Nas casas remanescentes passou a circular uma modalidade diversa de vida, de tal forma que essa, de dentro para fora, alterou a natureza das fachadas tornando-as irreconhecíveis. A nova vida em seus interiores, feito uma erosão controlada, de impulso invertido, pressionou paredes, varandas e vitrais destruindo a correspondência externa das várias linhas do desenho e impedindo que os olhos como os de Heládio (que nasceu e viveu parte da infância no bairro) pudessem em cada fachada reconhecer a feição familiar. (TAVARES, 2004, p. 9, grifos nossos)

A rua que Heládio observa é ao mesmo tempo estranha e familiar, e a percepção da mudança causa desconforto. À oposição eu $\times$ mundo acrescenta-se outra, passado $\times$ presente, em que o personagem passa a se sentir "por fora". As casas, que no exterior parecem as mesmas de sua infância, sofrem uma mudança interna, que faz perder o que há nelas do passado. Aqui o movimento, ao contrário, é de dentro para fora, sugerindo uma penetrabilidade entre realidades que parecem perfeitamente separáveis para Heládio e para o narrador - não custa ressaltar que o trecho em que este transcreve os pensamentos daquele começa com discurso direto e termina com indireto livre. A insistência nos movimentos entre "interior" e "exterior" não parece casual e mostra um grau de reflexão elevado.

A segunda cena é a da conversa entre Heládio e seu melhor amigo, Mauro, quando aquele finalmente confessa a inquietação causada pelo encontro no solário. Essa confissão, ensaiada nas duas visitas anteriores, tem aqui o papel de confirmar a hipótese de uma segunda história oculta ou verdadeira por trás da primeira, do processo de cura do protagonista: ela se desenvolve incessantemente por baixo da outra. No entanto, ela não é inteiramente revelada: Heládio fala do 
medo e do susto, mas deixa de lado a "oblíqua sensação de culpa, a inexplicável vergonha, o desassossego" (TAVARES, 2004, p. 123).

Veremos com mais calma esse ocultamento - e a revelação final — na próxima seção. Por enquanto ainda nos interessa pensar a oposição não dialética que Heládio e o narrador estabelecem entre "dentro" e "fora", colocada aqui de forma diferente. Ela se associa a um outro jogo de oposições: Heládio, "eu”, é o oposto de Mauro, o "outro", "aquele para quem se fala".

Como em um palco, cada um assume seu papel, que só existe na relação com o do outro. Mauro, "glutão", defende uma ideia muito bem articulada, posto que puramente retórica, acerca da Crítica da faculdade de julgar, de Kant, volume em espanhol colocado na mesa de cabeceira de Heládio. Descreve o narrador: "estira voluptuosamente as pernas, abre os braços espreguiçando-se e joga sem cerimônia o livro em cima da cama" (TAVARES, 2004, p. 127). O estado de espírito, a argumentação e toda a gesticulação do amigo se voltam para fora, para o mundo, e ele pode devorar o alvo que bem entender. Já Heládio está calado, "vagamente emburrado", e mais adiante chega a se enrolar no lençol em posição fetal, completamente passivo às investidas do amigo. Ele pensa, rumina e desdenha, mas nada faz.

O narrador facilita a continuidade dessa segunda cena à anterior ao explicar, sempre pelos olhos do protagonista: "Heládio foi um menino criado mais para dentro de casa, para cá do portão e Mauro sempre com um pé na rua" (TAVARES, 2004, p. 128, grifos nossos). O narrador volta a assimilar o vocabulário nitidamente tirado da construção mental de Heládio. E se vale a pena insistir nessa distinção narrador-personagem é porque buscamos investigar até que ponto existe distanciamento crítico em relação a esse homem ridicularizado no plano do enredo. Vamos, portanto, a uma terceira cena em que é possível identificar a persistência dessa questão.

Chegamos ao final do livro, quando, com o objetivo de fugir das ameaças no solário, Heládio toma subitamente a decisão de sair do hospital em uma cadeira de rodas. Toda a expectativa é armada para o clímax final, desde a caracterização do enfermeiro que empurra a cadeira à descrição minuciosa da recepção do hospital. Uma vez que a pobreza é "incontornável", "inabordável” (TAVARES, 2004, pp. 215; p. 218), o nosso protagonista quer sair ileso da fuga, manter intactas as suas certezas e a sua tão frágil vida interior. A escrita acelera e adquire o tom do desespero de Heládio, atravessando corredores com ele e Arlindo, o enfermeiro. E eis que, assim que sai na rua e vê os carros, a cadeira de rodas é brecada e Heládio é atirado ao chão como um pacote. Jogado à rua, o personagem finalmente é levado a romper a barreira que ele próprio criou entre dentro e fora, vendo o ridículo de sua existência "exibido à visitação pública" (TAVARES, 2004, p. 226). No final otimista do romance, o ciclo se quebra, e todos os medos mais íntimos de Heládio, representante de uma elite decadente, se expõem em praça pública. 
Esse desfecho nos leva a crer que o distanciamento crítico existe no plano do enredo e mesmo no do personagem, se é que é possível separar os elementos do livro desse modo. Todavia, sendo nosso objetivo entender se a linguagem do romance condiz com esse efeito geral ou é contraditória a ele, não podemos ainda chegar a uma conclusão. Até aqui, podemos perceber que o narrador de fato se aproxima a ponto de se confundir com o protagonista ao longo de todo o livro, conforme demonstramos, e que mesmo essa aproximação ganha transformações internas. No entanto, somente da comparação com os poucos momentos em que há intrusão de outros pontos de vista será possível avançar na confirmação de nossas hipóteses. Antes disso, vamos à observação de mais uma importante questão ligada ao narrador: a do acobertamento de uma realidade oculta.

\section{ACOBERTAMENTO DO MUNDO: O DESCOLAMENTO ENTRE NARRADOR E PROTAGONISTA}

A segunda estratégia complexa que vamos analisar, ao contrário da primeira, distancia narrador e personagem, e podemos caracterizá-la pelo acobertamento de uma realidade que, no entanto, preanuncia sua própria explosão. É por ela que o narrador sugere, à revelia do protagonista, o desfecho surpreendente do livro. Ocorre que aqui a escrita também é empolada, também parece um excesso quanto à matéria narrada. Vejamos agora como ela acontece e se também se justifica, apesar do descolamento com relação a Heládio.

São vários os momentos em que é possível observar a voz de um narrador que prepara terreno para o desfecho do livro. Como em um conto de ação única, é nessas pequenas intrusões que a narrativa mobiliza elementos para armar um esquema de necessidades, causando, ao final, a revelação da inevitabilidade da queda de Heládio - cena que, na primeira leitura, nos pega de surpresa. Selecionamos um desses momentos, mas citaremos alguns outros.

Voltemos às primeiras páginas, em que Heládio abre sua maleta e revela uma vontade de controle sobre a realidade, tendo tudo o que precisa ao alcance da mão. A esse clima de aconchego, porém, o narrador sobrepõe algo como um clima tenso, em que camadas de sentido oculto obscurecem a cena aparentemente pacata. Vejamos como isso acontece:

Heládio escuta o vento nas árvores. Abre a fresta da veneziana e observa o escuro lá fora; os ramos de uma velha árvore chegam até a janela; as folhas em movimento criam uma variação no escuro; uma trama diversa, ora mais clara, ora mais densa que a própria noite. (TAVARES, 2004, p. 11) 
O tom muda no início do parágrafo seguinte, na cena da maleta, mero elenco organizado de palavras. Aqui a linguagem é complexa, rebuscada. A justaposição pelo uso de ponto e vírgula supõe uma relação vaga entre os períodos, compondo um quadro pouco racional, de pinceladas soltas, que, não obstante, é detalhado e atento. A natureza mal visível através da janela, de vento, folhas de árvore e sabe-se lá o que mais, anuncia a existência de uma realidade obscura e não perceptível aos olhos de Heládio, que pode apenas vislumbrá-la sem nada decifrar.

O personagem parece apenas pressentir a fragilidade de uma realidade que periga ruir. Por isso, ele toma as devidas precauções: "evita sentar", "toma cuidado para não distender a pele lá embaixo", "tem medo do sofrimento" (TAVARES, 2004, p. 11). No entanto, arriscamos dizer que o dedo que insere o perigo é autoral, à revelia do personagem. Basta ver a natureza dos livros na cabeceira de Heládio: Histórias e sonhos, Diários íntimos e O cemitério dos vivos supõem em seus nomes um mistério, a noção de uma verdade oculta a olho nu. E o que dizer do conto "O inesperado"? A seleção desses títulos, enfim, não parece mera casualidade.

Avancemos algumas linhas mais. O narrador evoca, pelo pensamento do personagem, alguns dos momentos principais da vida deste, encontrando na mononucleose o motivo por trás dessa vontade que ele tem de entender as coisas e que ganha ainda mais força com a fissura no ânus:

[...] regimes, gema de ovo batida com conhaque, e uma outra vida apontando em segredo, do centro dessa fraqueza. Nos anos que se seguiram, esse gosto por cismar prendeu-se um pouco assim à lembrança da temperatura alterada, uma agitação de tipo especial [...]; uma agitação de movimento contrário ao fluxo do dia-a-dia, paralisando a outra, a do torvelinho dos negócios. [...] Uma invalidação contínua e inacabada, produzida por uma forma de agitação na outra, um truncamento, como hoje o mundo de sensações, que, com suas cores cambiantes, passa pelo céu alto e curvo mas se filtra pelo seu rabo na forma de uma dor aguda e dilacerante. (TAVARES, 2004, pp. 12-13)

Essa reflexão é interrompida de modo brusco pela entrada de um enfermeiro, quebrando totalmente o tom da escrita. Estamos naturalmente, mais uma vez, no interior dos pensamentos do personagem, confundidos com a voz do narrador. Heládio parece perceber, por inquietação ou agitação, a fragilidade do mundo controlado que constrói para si. A obscuridade da realidade para fora da janela, retomada no fim do trecho ("cores cambiantes"; "céu alto e curvo"), porém, é ressaltada pelo narrador, que parece anunciar o rompimento que ocorrerá 
assim que Heládio transpuser os limites do hospital.

É essa a construção - empolada - de um mundo oculto e latente, que anuncia o próprio rompimento. Ela perpassa todo o livro, tanto pela intrusão do mundo exterior quanto pelas construções mentais de Heládio. Assim como as árvores, a lona do solário contém uma realidade externa e destruidora: "As cortinas de correr, de lona amarela, descidas, aumentam o peso da luz do sol mas Ihe retiram as arestas, as pontas de aço, as frechas cruéis de uma claridade sem gradação" (TAVARES, 2004, p. 79). A insistência em palavras como "bago" (TAVARES, 2004, p. 19) e, mais frequentemente, "sumo" e "laranja" supõe a imagem de uma latência interna, prestes a estourar porque protegida por uma fina película, como a de uma fruta transparente. $O$ empolamento parece se justificar, portanto, pela noção de ocultamento ou disfarce: quanto mais camadas e dobras a linguagem tiver, menos será revelado ao leitor — que, no entanto, é capaz de nova compreensão em uma segunda leitura do livro.

Podemos também citar as construções mentais de Heládio, como a separação entre o "isso" (aquilo que se conta) e o "tudo" (que incorpora o inabordável, vergonhoso e secreto) nas reflexões sobre a conversa com Mauro. O fantasma está lá, cada vez menos disfarçado no discurso autoenganador do protagonista. E este de fato quebra as barreiras na cena final, que aborda longamente o tema do acobertamento pelos olhos de súbito conscientes de Heládio frente à leitura da carta do primo daquele homem que aparecera no solário:

Tem medo, medo, o seu medo se complica, tem medo do que não sabe, do que não soube. Só que agora o que não sabe está ali com ele, por trás, pelos cantos do hospital ou pela frente, adiantando-se a ele para zelar pela sua saída, o espia, o espiona, aguarda seus passos [...]. Ele se queria incógnito. Embuçado no seu mistério perfeitamente bobo. E os incógnitos são os outros. Anônimos, incógnitos, quantos? Um cortejo deles o segue. Está à mercê. (TAVARES, 2004, p. 214)

Heládio é pego de surpresa, e todo o seu sistema de acobertamentos é posto a nu: a aparência de controle que ocultava a realidade caótica; a toalete, as gorjetas, os livros, a aparência física, a fala empolada, todos encobridores da sua existência, na verdade, medíocre e comum; o nome do bispo falecido, que acoberta a personalidade "sensitiva" de Heládio; o comedimento, enfim, que o defende do ridículo, é tirado de cena, dando lugar, para o terror do personagem, à consumação de todos os seus medos, postos ao olhar do público. $O$ efeito seria trágico, não fosse o distanciamento do narrador. Vingado, o leitor ri. 


\section{QUANDO A CÂMERA CIRCULA}

Observados os movimentos de aproximação e distanciamento do narrador em relação ao protagonista de $O$ nome do bispo, podemos enfim compará-los aos raros momentos em que aquele assume o ponto de vista de outros personagens. Se a maioria deles está em uma lembrança infantil do protagonista, o que já mostra um enviesamento, cremos ainda assim ser produtivo olhar com alguma atenção para o ponto de vista de dois personagens específicos.

Deitado na cama do hospital, Heládio observa as mágicas ondulações do teto azulado e se transporta para a sala da casa de seus avós, em que o tio Oscar apresentará um espetáculo de mágica para crianças e adultos. Ele acaba de completar onze anos e está fascinado com o espetáculo por vir, mas o primeiro filtro que temos da cena não é o seu, e sim do tio-avô, d. Heládio Marcondes Pompeu. Ainda que o vejamos pela lembrança do protagonista, esse personagem se destaca, e vemos a cena também pelo moralismo do bispo. A presença deste, de certa forma, está lá: “Se consultado a respeito [...], d. Heládio teria advertido que: justamente ali, na candura e inocência de um espetáculo de mágicas, 'Ele' poderia se infiltrar para confundir os presentes com 'Seus' truques!" (TAVARES, 2004, p. 20) e "Pode-se bem pensar nas consequências funestas; e não apenas para as crianças presentes! D. Heládio teria advertido." (TAVARES, 2004, p. 21).

Esses dois exemplos mostram a realidade a partir do ponto de vista do bispo, que está filtrado; mas por quem? Certamente não apenas por Heládio, que, na ocasião, era apenas uma criança e estava ocupado demais aguardando o início do espetáculo. Podemos dizer que há aqui um jogo de mediações que envolve a memória coletiva da família Pompeu, e não de apenas um de seus representantes. A autoridade do bispo d. Heládio era tal que deixou seus traços na família Pompeu, passados adiante para o protagonista do livro. Não se trata, portanto, de um olhar direto do narrador para o personagem - assim como em outras câmeras, que apontam para o núcleo infantil da sala, para tio Oscar, para tia Clara. Ainda assim, vemos alguma destreza do narrador em incorporar a sintaxe dos pensamentos de outros personagens, que se torna ainda mais pomposa quando mostra o ponto de vista enviesado de $d$. Heládio ou mais ingênua e esperançosa quando aponta para o núcleo das crianças.

Em oposição à câmera que aponta para Heládio, encontramos outra mais interessante, que destoa do conjunto da obra. Na segunda parte do espetáculo, tio Oscar leva ao palco uma mulher ruiva, supostamente russa - na realidade, uma polaca, paixão passada do tio - , que desencadeia outra memória comum à família. A esposa de Oscar, irada de ciúmes, provoca uma lembrança à vovó Maroquinhas, narrada da seguinte forma: 
Vovó Maroquinhas lembra-se [...]; e ela vê:

Um outro passado, de dentro desse passado que se apresenta como presente, inflar feito vela hasteada vedando completamente o que veio depois (essa mesma sessão de mágicas) como se fosse o seu tempo anterior.

1912. Santos [...] Tio Oscar, de pé atrás do guarda-sol, acena para a figura ao longe, que se detém um instante e logo recomeça a andar. Minutos depois avisa tio Oscar então solteiro e muito jovem:

- Vou dar uma caminhada para os lados de São Vicente, mamãe. Volto daqui a pouco para ajudar com o guarda-sol.

Mas a luz oblíqua da tarde havia mudado o discreto aceno de tio Oscar atrás da lona do guarda-sol em uma agigantada e oscilante sombra na areia, e assim vovó Maroquinhas soube e surpreendeu a filha ao dizer com segurança e uma tristeza pouco expressa: - Lá vai ele. Vai ao encontro dela: a mulher casada.

(TAVARES, 2004, pp. 37-38)

Nesse trecho, estamos inteiramente imersos na dicção dessa outra personagem, incorporada pelo narrador praticamente à revelia de Heládio. A manutenção das designações "vovó" e "tio", segundo a nossa leitura, servem só à coerência com os nomes que já haviam sido apresentados. No entanto, quem vê é a vovó Maroquinhas, em um passado anterior ao nascimento do protagonista, e os detalhes da cena mostram um olhar feminino atento e investigativo: de que outra forma entender a interpretação que a senhora faz da sombra oblíqua à margem do guarda-sol?

O narrador do romance, portanto, é capaz de circular por outros pontos de vista além do de Heládio, incorporando outras sintaxes. Infelizmente, porém, são todos representantes de uma mesma camada social, o que não nos dá elementos suficientes para comparar a fundo as diferentes vozes. Com vovó Maroquinhas, temos o olhar feminino atento. Com o tio-avô d. Heládio, o moralismo católico. Contudo, nada impede que ambos tenham sido transmitidos ao nosso protagonista pela família, e ele poderia assim recompor os discursos com a imaginação, transcrita apenas pelo narrador.

O único momento do livro em que saímos realmente do ponto de vista de um personagem de pedigree e passamos a uma linguagem menos elitizada está nos contos populares passados a Heládio por Abérsia Maria de Jesus, a antiga empregada, nascida em Pernambuco. Ela conta as aventuras de Camões em Recife, representante da alta cultura transformado subitamente em herói de contos de fada. Ali a linguagem é popular, livre de ornamentos e excessos - contudo, ela aparece no discurso direto e jamais chega a ser incorporada pelo narrador. 
A cena é importante na medida em que marca o choque entre esses dois tipos de cultura, mas em nenhum momento essa barreira é superada pelo narrador, que não é capaz de incorporar o ponto de vista da personagem.

\section{CONCLUSÃO}

Feita a análise da posição do narrador nos mais importantes movimentos de câmera em relação aos personagens, podemos concluir que não temos elementos suficientes para afirmar que existe distanciamento crítico na linguagem. Se o ponto de vista de Heládio é dominante ao longo do livro, as poucas tentativas do narrador de se descolar dele apresentam uma linguagem similar, também rebuscada, além de pouco desenvolvida. Não podemos, portanto, dizer que esse empolamento chega a ter consciência crítica suficiente para colocar-se como ironia. Mimética na maior parte do tempo, ornamental em poucos casos, essa linguagem permite, porém, interessantes construções, como procuramos apontar especialmente nos movimentos de aproximação (na dinâmica dentro-fora) e descolamento do protagonista (com a noção de ocultamento do mundo). Quem ri é o leitor; e, se o narrador dá todos os recursos para tanto, não chega a se distanciar suficientemente da agonia do protagonista. I

RENATA CASTANHO - Mestranda do Departamento de Teoria Literária e Literatura Comparada da Universidade de São Paulo - USP, São Paulo, SP, Brasil. Este artigo foi produzido para a conclusão do curso "Tópicos de Cultura Brasileira Contemporânea: Poesia, Prosa, Cinema”, ministrado pelas professoras Ana Paula Pacheco e lumna Maria Simon no primeiro semestre de 2016 


\section{REFERÊNCIAS BIBLIOGRÁFICAS}

ARANTES, Paulo Eduardo. "Sofística da assimilação". In: Praga, vol. 8. São

Paulo: Ed. Hucitec, 1999.

DANTO, Arthur C. "Introduction: modern, postmodern, and contemporary". In: After the end of art. Contemporary art and the pale of history. Princeton: Princeton Univ. Press, 1997, pp. 3-19.

SIMON, lumna Maria; DANTAS, Vinicius. "Negativo e ornamental: um poema de Carlito Azevedo em seus problemas". In: Revista Novos Estudos, v. 91, nov. 2011, pp. 109-120.

TAVARES, Zulmira Ribeiro. O nome do bispo. 3. ed. São Paulo: Companhia das Letras, 2004. 